\title{
ECONOMIC AND LIFE CYCLE ANALYSIS OF MUNICIPAL SOLID WASTE MANAGEMENT FOR SMALL ISLANDS: ON-SITE MANAGEMENT SCENARIOS VERSUS OFF-SITE TRANSPORTATION
}

\author{
BOGIATZIDIS C. ${ }^{1}$ \\ KOMILIS D. ${ }^{2}$
}

School of Science and Technology, Open University of Greece

26335, Patras

Received: 23/12/2015

Accepted: $17 / 02 / 2015$

*to whom all correspondence should be addressed:

Available online: 19/02/2016

\begin{abstract}
A comparative economic and life cycle based analysis of five management scenarios for the solid waste generated in the island of Syros was conducted. The LCA part was performed with the LCA - IWM software. The four on-site waste management scenarios were: i) source separation of recyclable materials in combination with landfill disposal of the residuals (existing situation), ii) aerobic, windrow type, biological treatment (composting) with landfilling of residues, iii) anaerobic biological treatment (digestion) with landfilling of residues iv) aerobic mechanical biological treatment (MBT) and landfilling of residues. The off-site management scenario examined the transportation of the whole commingled wastes off the island for processing and disposal to the main mechanical and biological pretreatment plant in Athens. The results of analysis showed that the optimum waste management scenario in terms of environmental burdens (based on six environmental impact categories) and economics was off-site transportation, even when the specific landfill tax is included in calculations. The second best scenario in terms of environmental performance included the on-site aerobic MBT plant while the worst scenario was direct landfilling with mixed dry recyclables' recycling. On-site anaerobic digestion had less environmental burdens and was more expensive than open windrow composting. Threshold distances were calculated below which the transportation of municipal solid wastes from a small island is financially and environmentally beneficial.
\end{abstract}

Keywords: environmental burdens; islands; life cycle analysis; management; municipal solid waste (MSW).

\section{Introduction}

Municipal solid waste (MSW) management is still one of the most important and challenging environmental issues of our times. According to the 2008/98/EC directive, which defines the hierarchy in solid waste management actions in Europe, landfilling is the least desired solution, while prevention and minimization are the most preferable ones. In addition, the principle of proximity, meaning that wastes should not travel large distances for treatment and final disposal, is an axiom of the European legislation. Yet, objective criteria to define proximity are not provided. In addition, according to the 2008/98/EC directive, deviations from the waste hierarchy can occur for certain waste streams, if life cycle analyses results demonstrate the benefits of that deviation.

Life cycle assessment (LCA) in MSW has been extensively used (Koneczny and Pennington 2007; Liamsanguan and Gheewala, 2008; Khoo, 2009; Gentil et al., 2010; Manfredi et al., 2011; Song et al., 2013; Laurent et al., 2013). Using LCA, evaluation of MSW management systems performance can be conducted, 
enabling the comparative assessment between alternative management scenarios (Denison, 1996; Mendes et al., 2004; Finnveden et al., 2005; Koroneos and Nanaki, 2011; Antonopoulos et al., 2012; Parkes et al., 2015). In addition, examination of the optimization potential for the applied procedures for particular areas is allowed (Koroneos and Nanaki, 2011; Antonopoulos et al., 2012; Parkes et al., 2015).

Despite the extensive application of LCA in MSW management, limited research appears to exist on the management of solid wastes in small islands (Diaz, 2007; Willmott and Graci, 2012; Tallei et al., 2013; Zis et al., 2013; Malatesta et al., 2015; Shams Fallah et al., 2013). Most small islands (such as the ones in the Aegean sea, the Carribean, the Canary islands, the Phillipines etc) have a high seasonal waste generation variation, due to touristic activities, and a limited space to treat and dispose of the waste. In addition, economies of scale do not, usually, allow the construction of large waste treatment facilities on such relatively small areas. Recycling and source separation activities usually take place on-site and the collected dry recyclables are commonly transferred outside the islands, towards continental sites for processing in central facilities. The rest of the commingled stream is commonly landfilled.

Transportation of wastes outside the islands is rarely implemented, or even accounted for, due to the concern of the high transportation cost as well as due to the "principle of proximity" that pervails, at least in the management of MSW in Europe. Yet, transportation of some fractions of MSW outside the island could be thought of as a viable solution as long as the construction of small treatment plants on the island is economically prohibitive.

Environmental burden and life cycle analysis of solid waste management on small islands has rarely accounted for the transportation of waste outside the island. Actually, the few existing studies on waste management for small islands focus mostly on the economic assessment, and less on the environmental assessment, of on-site solutions. For example, a model of an integrated solid waste management system in an islandic region has been developed for the island of Corfu in the Ionian sea in Greece (Skordilis, 2004). The model's implementation in the area, designated as the most appropriate method for the waste disposal in Corfu, in terms of economics, the combination of recyclables' source separation and the composting of the organic waste fraction. However, environmental burdens were not accounted for in that work. In Green Island (Taiwan), local authorities realised that they would be forced in the future to transport wastes to the mainland. According to Chen et al., (2005), investment to an incineration plant would simply gain additional time during the investigation of alternative MSW strategies.

Tan and Khoo (2006) described the application of life cycle assessment for various waste management scenarios in the island of Singapore. The SimaPro ${ }^{\circledR}$ LCA model was used to carry out the environmental analysis of the scenarios under evaluation. Out of all the waste scenarios examined, source separation and recycling appeared to be the most appropriate technique to treat on-site the waste generated in the area under study.

Shamshiry et al., (2011) investigated alternative treatment scenarios of MSW in touristic regions such as Langkawi Island (Malaysia). Their work outlined the current solid waste management methods that were applied in Langkawi Island, but did not perform a comparison of other potential management methods.

Zis et al., (2013) examined alternative management methods of MSW in small islands, which at the moment included only open dumps. A comparison of the existing management method (dumping) with the transportation of waste and recyclables off-island was performed. Results designated economic benefits of waste transportation compared to the use of various treatment methods on each island.

Shams Fallah et al., (2013) examined three MSW management scenarios in Lavan island in Iran, by means of a LCA analysis adopting the Eco-indicator 99 environmental impact comparison method. The enviromental analysis results promoted the scenario of landfilling combined with recycling, incineration and composting, as the optimum treatment option.

An investigation of potential options for treatment of MSW in the island of Malta for energy recovery was carried in the paper of Pirotta et al., (2013). In conclusion, incineration and combined heat and power production appeared to be the optimum treatment method on site. Yet, this was a case that involved a rather large island with more than 400,000 inhabitans. 
As shown from the above, no analysis of the solid waste management system has been tackled in the literature when it comes to clustered small islands, with a population of less than around 20,000 inhabitants, as is the case of most islands in the Aegean archipelago in Greece.

In this study, alternative on-site MSW management scenarios were compared for the island of Syros in Greece. Syros can be considered as representative of small islands in Greece (small islands were defined in this study as the ones with a permanent population of less than 30,000 equivalent inhabitants per year). Apart from the 4 on-site management scenarios examined, a fifth off-site management scenario was investigated that included the transportation of wastes outside the island and their treatment in a central facility. This is considered the main novelty of this work, as this aspect of transporting municipal solid wastes outside the island has been rarely tackled in MSW management economic and environmental studies of islandic regions. The LCA and economic analysis was performed with the LCA-IWM software which is dedicated to MSW economic assessment and environmental assessment. In all examined management scenarios separate collection of MSW was assumed to be implemented. Further discussion on the fact that MSW source separation is important in solid waste treatment is given in Calabró (2010).

\subsection{The case study: the Island of Syros in Greece}

The Aegean archipelago has more than 2500 islands and islets. Syros belongs in the archipelago of Cyclades and is the capital of the homonymous province. It has an area of $84 \mathrm{~km}^{2}$ with one municipality and a population of approximately 22,000 permanent inhabitants and an average municipal solid waste production of around 14,000 ton/year (Table 1). Its equivalent population (i.e. including seasonal tourism) is estimated to be between 27,000 and 30,000 people.

MSW generation rates (quantities in $\mathrm{t} / \mathrm{y}$ ) were based on the weight records of MSW entering the island's main municipal landfill site for year 2012. In addition, the quantities of the recyclables generated by the island were based on records of a central MRF in Athens (during year 2012 as well) that ultimately receives those recyclables. Table 1 present the approximate composition and generated quantities of the landfilled MSW and of the dry recyclables generated in the island during 2012.

\section{Methodology and case study}

\subsection{Description of the LCA-IWM software}

\subsubsection{Assessment tool}

The LCA-IWM assessment tool was the software used for studying the proposed MSW scenarios in this study (Den Boer et al., 2005). LCA-IWM assessment tool is a supporting mechanism of strategic options in MSW management, through which modelling of different processing systems is enabled. Modelling becomes possible through the sub-models developed within the basic assessment software. These submodels represent individual management processes, such as temporary storage, collection, transport and further processing and/ or disposal. The method used to calculate the environmental burdens was the CML 2001 (Guinee et al., 2001) that includes six environmental impact categories. The LCA-IWM, in addition to the LCA based evaluation of the environmental impacts, enables the economic assessment of the individual management scenarios.

\subsubsection{Prognostic tool}

LCA-IWM prognostic tool is the software that enables forecasting of MSW generation quantities and composition in a specified timeframe, usually 10 years, through correlation of the solid waste production rates with particular socio-economic trends of the area under study. The final results of the prognostic tool that refer to composition and quantity of MSW are imported into the assessment tool as the primary data to form the functional unit, which is common for all the alternative MSW scenarios under study. It is clarified that in specific software used here (LCA-IWM), the prognostic tool is a separate routine that uses past data (prior to 2012) to predict the amounts of wastes generated in 2012. The functional unit (see 2.1.3) was, therefore, the amount of wastes produced during that year (in tons), as predicted by the 
prognostic tool, and was similar for all management scenarios to allow comparisons. We selected 2012, since accurate waste data were available for that year for the island of Syros

Table 1. Commingled MSW and dry recyclables' generation rates and composition in the island of Syros based on 2012 records

\section{Residuals (commingled MSW) directed to the landfill}

\begin{tabular}{|c|c|c|}
\hline Category & Composition (\%)* & Quantity (t/y) \\
\hline Ferrous Metals & 2.3 & 242.9 \\
\hline Non-Ferrous Metals & 1.2 & 125.7 \\
\hline Cardboard/ Paper/ Carton & 27.7 & 2949 \\
\hline Glass & 7.1 & 756 \\
\hline Plastic & 20.7 & 2203 \\
\hline Wood & 0,5 & 53.3 \\
\hline Inert materials & 0.4 & 40.5 \\
\hline Fabrics & 2.4 & 253.5 \\
\hline Composite materials & 3.2 & 338.8 \\
\hline Contaminated materials & 0.4 & 40.5 \\
\hline Hygiene products & 4.1 & 434.6 \\
\hline Other & 1.7 & 178.9 \\
\hline Organics & 28.5 & 3036 \\
\hline Total & 100.0 & 10653 \\
\hline \multicolumn{3}{|c|}{ Dry recyclables directed to the MRF } \\
\hline Category & Composition (\%)* & Quantity (t/y) \\
\hline Printed paper & 28.3 & 620 \\
\hline Packaging paper & 42.0 & 920.3 \\
\hline Glass & 8.0 & 174.4 \\
\hline Iron & 2.5 & 54.8 \\
\hline Aluminum & 0,9 & 19.7 \\
\hline Plastic & 2.7 & 59.2 \\
\hline PET & 4.0 & 87.6 \\
\hline HDPE & 3.1 & 67.9 \\
\hline LDPE & 4.4 & 96.4 \\
\hline Other & 4.1 & 89.8 \\
\hline Total & 100.0 & 2190 \\
\hline
\end{tabular}

*: Bourtsalas et al., (2011)

According to Table 1, it appears that the recycling (source separation) participation rate in the island of Syros (for year 2012) was $17 \%$. The principal components of the commingled MSW were organics and paper wastes, being at around $28 \% \mathrm{wb}$ each, whilst plastics wastes were present at around $20 \% \mathrm{wb}$. In the dry recyclables stream, packaging paper and printer paper were the two dominant components at $42 \%$ and $28 \%$, respectively.

\subsubsection{Functional unit and boundaries}

The functional unit was the total amount of MSW collected in Syros in year 2012 namely 13,400 t/y. As far as the boundaries are concerned, the starting point was when waste entered the waste management system (i.e. in containers in the curbside). The MSW collection and transportation within the city, towards the storage station (with regard to the recyclables) and towards the landfill / treatment facilities within the island for the rest of the fractions (commingled MSW, organic fractions) were included within the system boundaries. The transportation of the source separated dry recyclables from the storage location in the island to the recyclable processing facilities in mainland Greece was not accounted for. In addition, neither the environmental burdens associated to the processing of recyclables in that MRF was accounted 
for. This was done since the amounts of the source separated recyclables were similar under all five scenarios.

The cost (investment and operating) and environmental burdens of all treatment and disposal facilities of all four on-site management scenarios were also accounted for. In the fifth (off-site) scenario, the transportation of all commingled MSW from the island to the main landfill facility in continental Greece was included in the analysis. However, the cost and environmental burdens associated to the treatment / disposal of the transported MSW in the continental site (outside the island) were not included in the LCA. This was done, since the treatment / disposal facilities in Athens already exist and do not have to be constructed as in the case of the other four scenarios. The environmental burdens of the MSW treated and landfilled outside the island were also not accounted for in the analysis, since they were considered to be outside the insular limits. That is, the boundaries of the analysis were the island itself. Therefore, our LCA was limited to a local (insular), rather than a global scale as pursued in some LCA studies (Calabró et al., 2015). To our opinion, it is really hard, and sometimes unfeasible, to perform a LCA on a truly global scale. For example, in a global scale, one would have to include the emissions generated by the potential transportation of the recyclables recovered from the mainland facilities to other processing sites for further processing, or to account for the landfill emissions associated with those insular wastes. In addition to that, there were limitations of the specific software used here, since, when a new landfill is introduced in this software, both the construction cost and the environmental burdens need to be accounted for. This would complicate the analysis, since the landfills and the other mainland facilities have been already operating. The boundaries for each scenario are included in Figures 1 to 5 (colored in black), whilst the red color indicates the processes and links that were not accounted for in the whole analysis (outside the boundaries).

\subsubsection{Environmental Assessment Indicators}

The following environmental impact categories have been selected for the assessment of waste management scenarios according to CML 2001 (Guinee et al., 2005):

1. Depletion of Abiotic Resources: Its implementation within MSW scenarios assessment enables evaluation of environmental benefits that result from recycling and energy recovery. It is obvious that recycled and recovered resources would otherwise have to be re-extracted / reproduced as virgin materials.

2. Climate Change (Global Warming): Through this indicator, impacts of MSW management that contribute to the greenhouse effect (i.e. fossil fuel derived carbon dioxide, biogenic methane, $\mathrm{N}_{2} \mathrm{O}$ ) are assessed.

3. Human Toxicity: This indicator evaluates the effects of substances that are toxic to human health (i.e. $\mathrm{SO}_{\mathrm{x}}, \mathrm{CO}$, hydrocarbons, $\mathrm{NO}_{\mathrm{x}}$, heavy metals).

4. Photo-oxidant Formation: This indicator evaluates the negative impacts of emissions generated during landfilling and thermal processing that form more potent chemicals under the reaction with light (i.e. VOCs excluding methane, $\mathrm{NO}_{\mathrm{x}}$ ).

5. Acidification: This indicator is related to the impacts of acidic gaseous emissions, such as $\mathrm{SO}_{x}$ and $\mathrm{NO}_{x}$ on soil, water and environment.

6. Eutrophication: This indicator is related to the eutrophication impact resulting from the emissions of nitrogen $\left(\mathrm{NO}_{\mathrm{x}}, \mathrm{NH}_{3}\right)$ and $\mathrm{P}$ compounds to water bodies.

Final results of the impact assessment are expressed in normalized and weighted equivalent units (equivalent units per inhabitant - IE), according to CML (2001). The weight coefficients were actually taken equal to 1 for all impact categories. Note that negative normalized equivalent units can be calculated and this indicates net environmental benefits. For example, if a process produces recyclables that can replace virgin materials, then an environmental impact category (e.g. abiotic resources) might result in negative net equivalent units. This indicates that the recycled materials produce fewer pollutants compared to the 
ones generated by the extraction and processing of the virgin materials that those recyclables replace. Positive equivalent units indicate net environmental burdens.

\title{
2.2. The MSW management scenarios
}

There were five MSW management scenarios in this study. The four were based on on-site management and the fifth on transportation and off-site management. Note that the term "residuals" refers to commingled MSW, whilst the term "biodegradables" refers to the organic fraction of MSW (OFMSW). The five scenarios are explained in detail below:

Scenario 1: Direct landfilling of commingled MSW (residuals) with source separation of recyclables. This scenario, which resembles the current situation in Syros, is source separation and collection of recyclable materials with direct landfilling of the residuals (Figure 1). It consists of two flow streams: 1. Commingled MSW (residuals) and 2. Source separated mixed dry recyclables (MDR). The source separated MDR are stored in waste transfer (practically storage) stations (WTS), loaded on trailer trucks and ultimately transported (by ship) to a material recovery and processing facility in the mainland (Athens). The shipping of those recovered MDR off-island was not accounted for in the overall analysis, since this amount was always constant among all five scenarios.

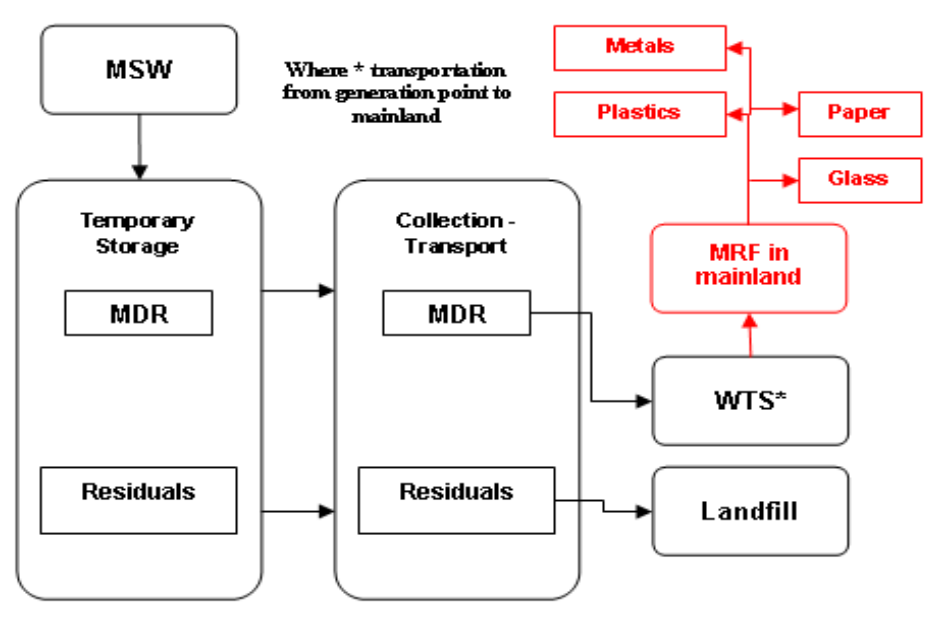

Figure 1. Flow diagram for scenario $1^{\text {(a) }}$

\begin{abstract}
${ }^{(a)}$ MSW: commingled MSW; WTS: Waste transfer (storage) station for MDR; MRF: material recovery facility; MDR: mixed dry recyclables; *: transportation from generation point to mainland. Red colour indicates processes and links that are outside the economic and life cycle analysis
\end{abstract}

Scenario 2: Aerobic biological treatment (composting) of the OFMSW with source separation of recyclables and landfilling of residuals (Figure 2). This scenario includes three flow streams: 1. Commingled MSW (residual), 2. Source separated MDR, and 3. Source separated organic fraction of MSW (OFMSW). The same flow pattern as in scenario 1 applies for residual waste and MDR. However, the one additional stream, namely that of the source separated OFMSW, is directed for further processing in the open-type windrow based composting plant that has no intensive mechanical pretreatment step. The residues of the composting plant are landfilled in the island's landfill, whilst the stabilized organic fraction of MSW (considered low quality compost due to the lack of intensive mechanical pretreatment) is directed to the landfill for use as landfill cover. The composting facility was sited next to the landfill site. According to the software, the compost derived from the process is assumed to be of low quality (i.e. stabilized organic waste), which is a conservative approach during the overall analysis.

Scenario 3: Anaerobic biological treatment (digestion) of the OFMSW with source separation of recyclables and landfilling of residuals (Figure 3). This scenario consists of the same flow streams as for scenario 2. The source separated OFMSW is transported to an anaerobic digestion plant. Energy is recovered and utilized on-site from the process and solid residues during the initial pretreatment step, as well as the 
digestate after the anaerobic digestion process, are disposed of to the landfill, as in the previously described scenario. The anaerobic digestion treatment plant is sited next to the insular landfill site.

Scenario 4: Aerobic mechanical biological treatment (MBT) of the residuals and source separation of the recyclables (Figure 4). This scenario consists of two flow streams: 1. Commingled MSW (residual), 2. Mixed Dry Recyclables. The same flow pattern as in the first scenario applies here for MDR. The residual MSW is transferred for process to an aerobic MBT facility and residues of treatment are disposed of in a landfill. The stabilized organic fraction derived from the aerobic MBT plant is used again as landfill cover in the local landfill. The RDF material and the (potential) extra recyclables derived from the MBT plant are considered to be transported outside the island (similar to the MDR). This transport is not accounted for in the analysis. The MBT plant is sited near the landfill site.

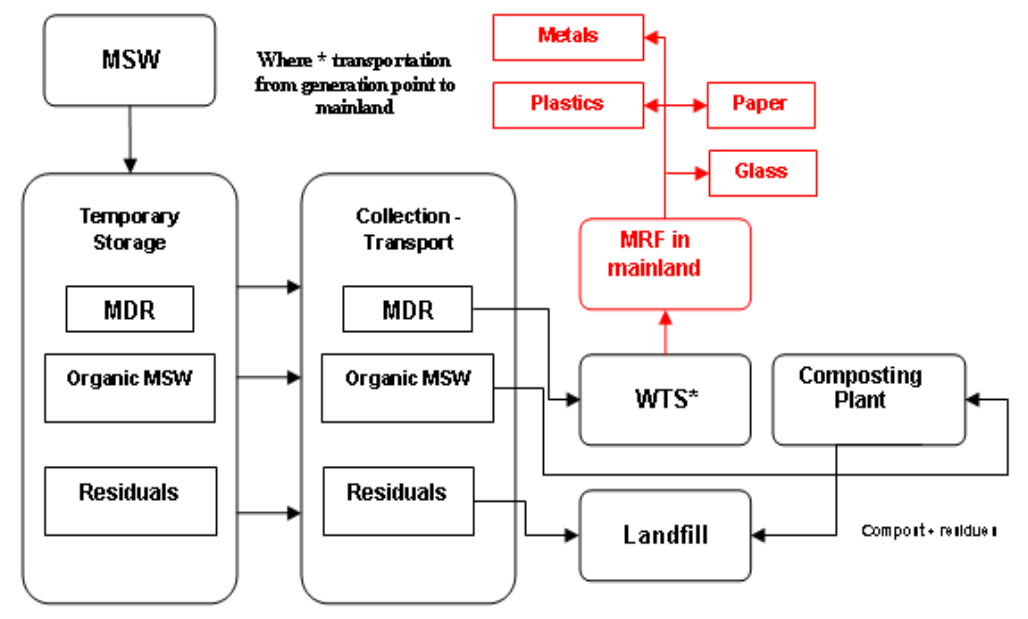

Figure 2. Flow diagram for scenario $2^{(\mathrm{a})}$

${ }^{(a)}$ MSW: commingled MSW; WTS: Waste transfer (storage) station for MDR; MRF: material recovery facility; MDR: mixed dry recyclables; *: transportation from generation point to mainland. Red colour indicates processes and links that are outside the economic and life cycle analysis.

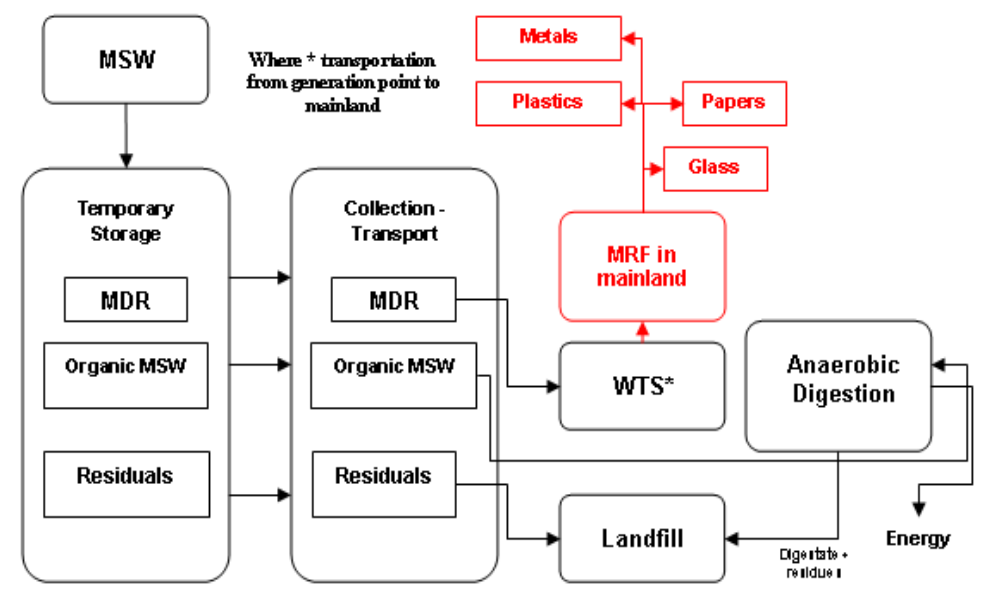

Figure 3. Flow diagram for scenario $3^{(a)}$

${ }^{(a)}$ MSW: commingled MSW; WTS: Waste transfer (storage) station for MDR; MRF: material recovery facility; MDR: mixed dry recyclables; *: transportation from generation point to mainland. Red colour indicates processes and links that are outside the economic and life cycle analysis.

Apart from the on-island management scenario, an off-site scenario was considered namely: 


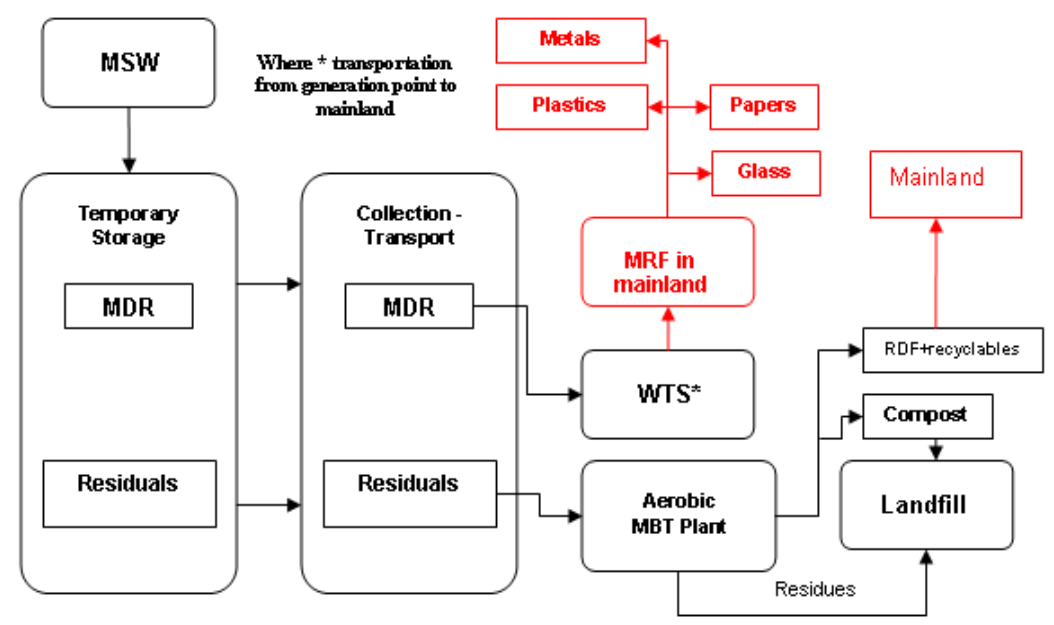

Figure 4. Flow diagram for scenario $4^{\text {(a) }}$

(a)MSW: commingled MSW; WTS: Waste transfer (storage) station for MDR; MRF: material recovery facility; MDR: mixed dry recyclables; *: transportation from generation point to mainland. Red colour indicates processes and links that are outside the economic and life cycle analysis.

Scenario 5: Transportation of MSW to mainland (Athens) for further processing to an existing MBT facility located in Liosia Athens and source separation of the recyclables (Figure 5): This scenario consists of two flow streams: 1. Mixed/ other MSW (residual/ other waste) and 2. Mixed Dry Recyclables (MDR). Residual waste are collected and considered to be stored in the island in the same WTS.

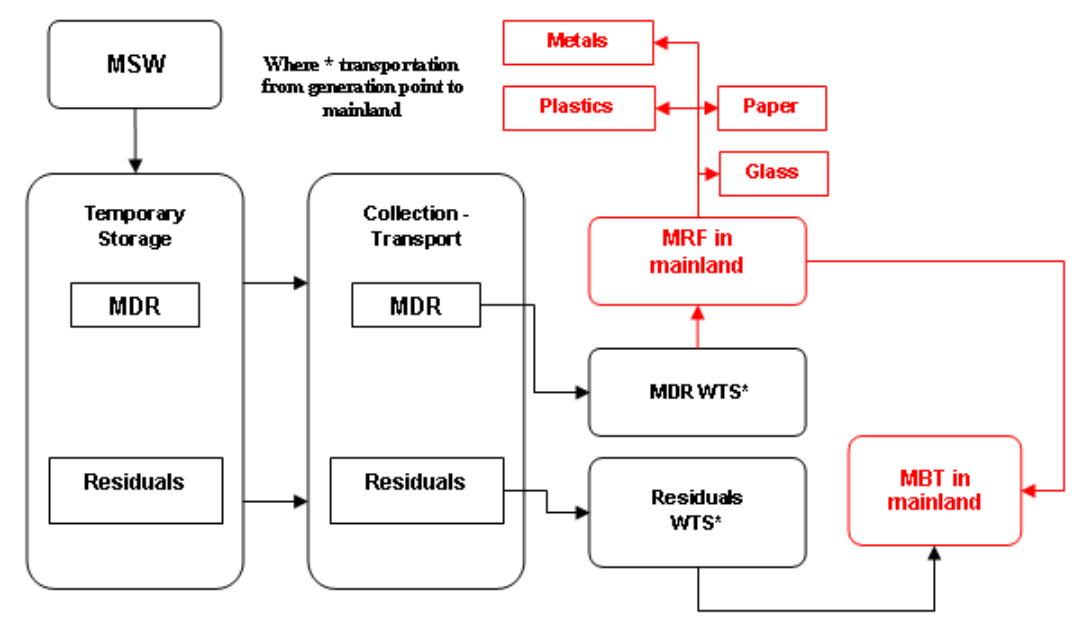

Figure 5. Flow diagram for scenario $5^{(a)}$

(a)MSW: commingled MSW; WTS: Waste transfer (storage) station for MDR; MRF: material recovery facility; MDR: mixed dry recyclables; *: transportation from generation point to mainland. Red colour indicates processes and links that are outside the economic and life cycle analysis

Then, the commingled MSW are loaded on trailer trucks and transported (by ship) for processing at a 1200 $\mathrm{t} / \mathrm{d}$ design capacity MBT facility in Liosia (Athens), where RDF, stabilized organic MSW fraction (compost) and recyclables are generated. The production of those last 3 co-products is not part of the LCA analysis. On the other hand, the transportation cost to the continental facility, as well as the gate fee that the facility charges to the municipality of Syros is included in the analysis. The source separated recyclables have the same fate (and quantities) as in the previous scenarios. Therefore, scenario 5 (transportation scenario) accounts only for the transportation cost and does not include construction of new facilities (treatment plants, landfill) but solely the purchase of vehicles to collect the waste within Syros (as is true for all other previous four on-site scenarios). 


\subsection{Technical Assumptions}

The technical assumptions made in this study are summarized in Table 2.

Table 2. Modeling assumptions as used in LCA-IWM (cost prices are for year 2013)

\begin{tabular}{|c|c|}
\hline MSW generation rate (kg/capita/year) & $634^{(1)}$ \\
\hline$\%$ inhabitants that use corresponding bins & $70 \%$ (MDR), $95 \%$ (Residuals), 70\% (Bio-Waste) ${ }^{(2)}$ \\
\hline Collection Frequency (d / yr) & 156 (MDR), 208 (Residuals), 208 (Bio-Waste) $^{(2)}$ \\
\hline Types of vehicles of MSW Collection & Standard (MDR, Residual), Alternative (Bio-Waste) ${ }^{(2)}$ \\
\hline Bins size/ Material & 2500 L/steel (MDR), 770 L/plastic (Residuals, Bio-Waste) ${ }^{(2)}$ \\
\hline Average Filling Rate of Bins (\%) & $85 \%^{(2)}$ \\
\hline Fuel Consumption $\left(\mathrm{I} \mathrm{km}^{-1}\right)$ & 0.27 (standard), 0.54 (trailer) ${ }^{(3)}$ \\
\hline $\begin{array}{l}\text { Within island driving distance (City - } \\
\text { Facility) in km }\end{array}$ & $15^{(2)}$ \\
\hline $\begin{array}{l}\text { Real (marine) off-island transportation } \\
\text { distance (island - mainland) in km }\end{array}$ & 200 \\
\hline $\begin{array}{l}\text { Corresponding driving (terrain) distance } \\
\text { (island - mainland) in km }\end{array}$ & $920^{(4)}$ \\
\hline Ticket cost by ship (Syros- Piraeus) (€) & $460^{(5)}$ \\
\hline $\begin{array}{l}\text { Transport cost per ton-km (marine } \\
\text { transportation) (€/ton-km) }\end{array}$ & $0.16^{(4)}$ \\
\hline $\begin{array}{l}\text { Transport Cost (road transportation) } \\
\qquad(€ / \text { ton-km) }\end{array}$ & 0.05 (standard), 0.0351 (trailer) ${ }^{(4)}$ \\
\hline Fuel cost $(€ / I)$ & $1.3^{(2)}$ \\
\hline Types of vehicles of MSW Transportation & Transport vehicle/ trailer (MDR), Alternative (Bio-Waste) ${ }^{(2)}$ \\
\hline Marine-Road distance relation & $\begin{array}{c}1 \mathrm{~km} \text { marine distance }=3.2 \mathrm{~km} \text { road distance (standard vehicle) } \\
1 \mathrm{~km} \text { marine distance }=4.6 \mathrm{~km} \text { road distance (trailer) }{ }^{(4)}\end{array}$ \\
\hline Vehicles Capacity (in tonnes) & Standard 7 ton, Alternative 7 ton, Transportation 14 ton ${ }^{(1)}$ \\
\hline Crew size per vehicle & $2^{(2)}$ \\
\hline Operating periods (in $\mathrm{d} /$ year or $\mathrm{h} /$ day) & $\begin{array}{l}\text { Aver. Op. time } / \text { vehicle }=240 \mathrm{~d} / \text { year }^{(2)} \\
\text { Max. op. time } / \text { crew }=7 \mathrm{~h} / \text { day }^{(2)}\end{array}$ \\
\hline Vehicle purchase cost (in $€$ ) & $\begin{array}{c}140.000\left(^{(S t a n d a r d}\right)^{(2)}, 200.000(\text { Transport })^{(2)}, 120.000 \\
(\text { Alternative) })^{(2)}\end{array}$ \\
\hline Salary after taxes (in €) & $\begin{array}{l}\text { Average hourly cost of vehicle driver/ productive hour }=€ 6^{(2)} \\
\text { Average hourly cost of collector/per productive hour }=€ 7^{(2)}\end{array}$ \\
\hline Facilities' Design Capacities (in tn/year) & $\begin{array}{l}\text { Landfill: } 10000 \text {, Recycling Facility: } 5000 \text {, Composting/ Anaerobic } \\
\text { Digestion plant: } 3500, \text { MBT plant: } 12000^{(2)}\end{array}$ \\
\hline Time frame of analysis (in years) & 20 for all treatment facilities ${ }^{(2)}$ \\
\hline Avoided Heat Production Mix (\%) & $100 \%$ Heavy Fuel ${ }^{(2)}$ \\
\hline
\end{tabular}
(1) Result produced through LCA-IWM Prognostic Model based on collected waste quantities data for year 2012 for the island of Syros.

(2)User defined data

(3) Manufacturers data

${ }^{(4)}$ Correlation between road - sea distance: 14 tnTruck Trasp. Cost per km (by ship) $=€ 460 \div 200 \mathrm{~km}=€ 2.3 / \mathrm{km}$

Transportation cost per tn-km (by ship): $€ 2.3 \div 14 \mathrm{tn}=€ 0.16 / \mathrm{tn}-\mathrm{km}$

Transportation cost per $\mathrm{km}$ (collection vehicle): $€ 1.3 \times 0.27 \mathrm{lt} / \mathrm{km}=€ 0.351 / \mathrm{km}$

Transportation cost per $\mathrm{km}$ (20 tn container truck): $€ 1.3 \times 0.54 \mathrm{lt} / \mathrm{km}=€ 0.702 / \mathrm{km}$

Transportation cost per tn-km (collection vehicle): $€ 0.351 / \mathrm{km} \div 7 \mathrm{tn}=€ 0.050 / \mathrm{tn}-\mathrm{km}$

Transportation cost per tn-km (20 tn container truck): €0.702/km $\div 20 \mathrm{tn}=€ 0.0351 / \mathrm{tn}-\mathrm{km}$

Correlation of road-sea distance: $1 \mathrm{~km}$ of sea distance corresponds to $€ 0.16 / \mathrm{tn}-\mathrm{km} \div € 0.050 / \mathrm{tn}-\mathrm{km}=3.2 \mathrm{~km}$ of road distance traveled by collection vehicle

Respectively road-sea distance: $1 \mathrm{~km}$ of sea distance corresponds to $€ 0.16 / \mathrm{tn}-\mathrm{km} \div € 0.0351 / \mathrm{tn}-\mathrm{km}=4.6 \mathrm{~km}$ of road distance traveled by 20tn container truck. Corresponding road distance between Syros - Piraeus $=4.6 \mathrm{~km} \times 200=920 \mathrm{~km}$

(5) Price based on Ticket Agencies data (personal communication with travel agents) 


\section{Results and discussion}

\subsection{Environmental Assessment}

Figure 6 presents the results produced by the LCA - IWM model. In this graphical representation, the environmental performance of each scenario is illustrated. Note that the equivalent units per inhabitant (IE) are reported after the normalization / weighing that was performed under the CML (2001) methodology.

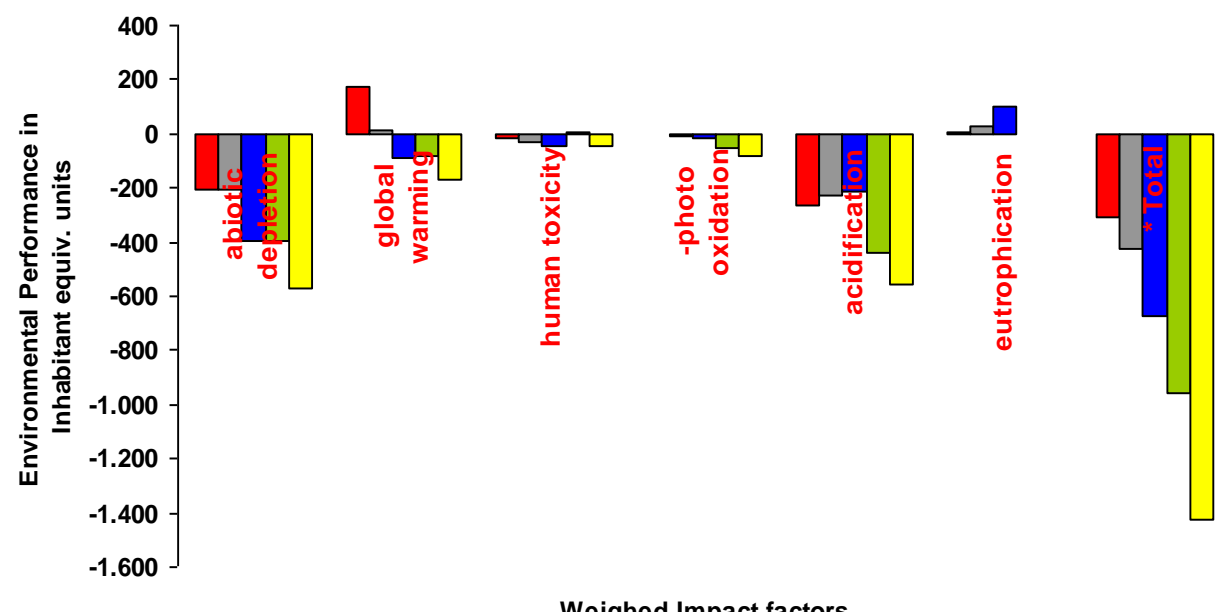

$\square$ Existing Method $\square$ Composting $\square$ Anaerobic Digestion $\square$ MBT $\square$ Transportation to mainland

Figure 6. Equivalent units of the six environmental impact categories of the five management scenarios (existing method is scenario 1 )

By summing up all normalized IE per scenario, the optimum scenario becomes the off-site transportation in combination with source separation of the MDRs (scenario 4). That scenario achieves approximately 1425 IE with the MBT following with -956 IE. Direct landfilling, composting and anaerobic digestion "generate" $-307,-427$ and $-672 \mathrm{IE}$, respectively. The environmental impact assessment equivalent units per inhabitant (IE) for each category as well as the total IE for all five scenarios are shown in Figure 6 (last columns). According to Figure 6 , the off-site transportation seems to be by far the beneficial scenario with regard to all six environmental impact categories. This is a result of the fact that no building of new facilities is necessary as in the case of all other 4 scenarios. In addition, since MSW are being further processed and disposed in mainland's facilities, no emissions from the processing itself are accounted for (since the boundaries of the system was considered the island itself). Direct landfilling has the highest global warming environmental impact, which is mainly attributed to the relatively high generation of methane by the biodegradables disposed of to the landfill. The MBT scenario (scenario 4) is the second most beneficial scenario in terms of total environmental impacts (sum of the IE of the 6 impact categories). This is because the MBT landfill accepts relatively stabilized wastes with very low methane potential. Actually, in scenario 4 (aerobic MBT), there is a reduction of those emissions by up to $95 \%$ compared to the existing scenario. In addition to that, the volume of disposed MSW decreases up to $60 \%$, while quality and quantity of produced leachate and air emissions is significantly improved compared to the existing scenario of direct landfilling.

According to Table 3, almost none of the scenarios under study can meet simultaneously all the recovery and recycling targets set by directive 2008/98/EC (Table 3). On the other hand, Table 3 shows that it is scenario 4 (the aerobic MBT) and scenario 5 (transportation) which better meet the overall recycling targets. Actually, scenario 4 achieves the highest recycling rate (23\%), followed by scenario 5 (17\%). Also the landfilling of biodegradables is lowest in scenario 4 as well. 
Table 3. European recycling targets achieved per scenario

\begin{tabular}{lcccccc}
\hline \multicolumn{1}{c}{ Target } & $\begin{array}{c}\text { Target } \\
\text { rates set } \\
\text { by } \\
2008 / 98 / \\
\text { EC (\%) }\end{array}$ & $\begin{array}{c}\text { Rates } \\
\text { attained in } \\
\text { Scenario 1 } \\
\text { (direct } \\
\text { landfilling) }\end{array}$ & $\begin{array}{c}\text { Rates } \\
\text { attained in } \\
\text { Scenario } 2 \\
\text { (windrow } \\
\text { composting) }\end{array}$ & $\begin{array}{c}\text { Rates attained } \\
\text { in Scenario 3 } \\
\text { (anaerobic } \\
\text { digestion) }\end{array}$ & $\begin{array}{c}\text { Rates } \\
\text { attained in } \\
\text { Scenario 4 } \\
\text { (aerobic } \\
\text { MBT) }\end{array}$ & $\begin{array}{c}\text { Rates } \\
\text { attained in } \\
\text { Scenario 5 } \\
\text { (transportati } \\
\text { on to } \\
\text { mainland) }\end{array}$ \\
\hline $\begin{array}{l}\text { Overall } \\
\text { Recycling }\end{array}$ & $55 \%$ & $11 \%$ & $9 \%$ & $9 \%$ & $23 \%$ & $17 \%$ \\
\hline Recycling Glass & $60 \%$ & $19 \%$ & $19 \%$ & $19 \%$ & $27 \%$ & $27 \%$ \\
\hline Recycling Paper & $60 \%$ & $23 \%$ & $23 \%$ & $23 \%$ & $39 \%$ & $39 \%$ \\
\hline $\begin{array}{l}\text { Recycling } \\
\text { Metals }\end{array}$ & $50 \%$ & $1 \%$ & $1 \%$ & $1 \%$ & $56 \%$ & $11 \%$ \\
\hline $\begin{array}{l}\text { Recycling } \\
\text { Plastics }\end{array}$ & $23 \%$ & $8 \%$ & $7 \%$ & $7 \%$ & $10 \%$ & $10 \%$ \\
\hline $\begin{array}{l}\text { Landfilling of } \\
\text { Biodegradable }\end{array}$ & $35 \%$ & $130 \%$ & $122 \%$ & $122 \%$ & $39 \%$ & $130 \%$ \\
\hline
\end{tabular}

\subsection{Economic Assessment}

According to the economic analysis performed by LCA - IWM (see Figures 7,8 ), it can be deduced that the less costly MSW management scenario for the area under study is the off-site transportation (Scenario 5). Note that for all four first scenarios, new facilities and equipment need to be constructed and purchased, which explains the final total cost for those options (range from $€ 46$ to $€ 134 / t$ ). This was done in order to facilitate comparison among the scenarios. That is, the existing infrastructure in Syros (existing vehicles and existing landfill) is not taken into account in the economic analysis. As a result of the above, i.e. the need for facility construction in the first four scenarios, scenario 5 becomes the least expensive in terms of total cost, being equal to $€ 42 / \mathrm{t}$. Figure 7 illustrates the investment cost for each of the scenarios.

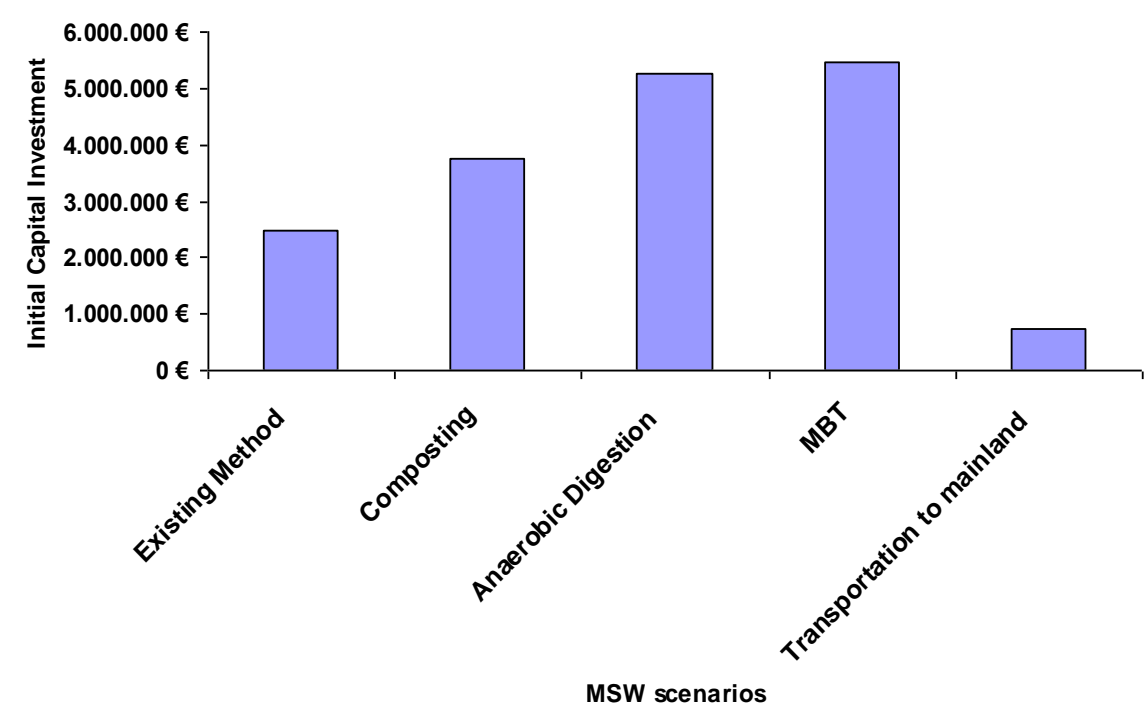

Figure 7. Investment cost for the facilities/equipment needed for each scenario (existing method is Scenario 1)

According to Figure 7, the highest capital cost is observed in the MBT scenario (scenario 4) whilst the lowest capital cost is observed, as expected, for the off-site transportation scenario. Figure 8 present the total cost (investment and depreciated operating cost) for all scenarios as calculated by LCA-IWM. According to that, off-site transportation (scenario 5) is the least expensive with a unit cost of $€ 42 /$ ton, whilst the aerobic MBT scenario (scenario 4) is the most expensive at $€ 134 / t$. Anaerobic digestion is the 
second most expensive methodology and this cost is practically comprised of the transportation cost to the mainland. Anaerobic digestion is more expensive than composting with total costs at $€ 110 / t$ and $€ 79 / \mathrm{t}$, respectively.

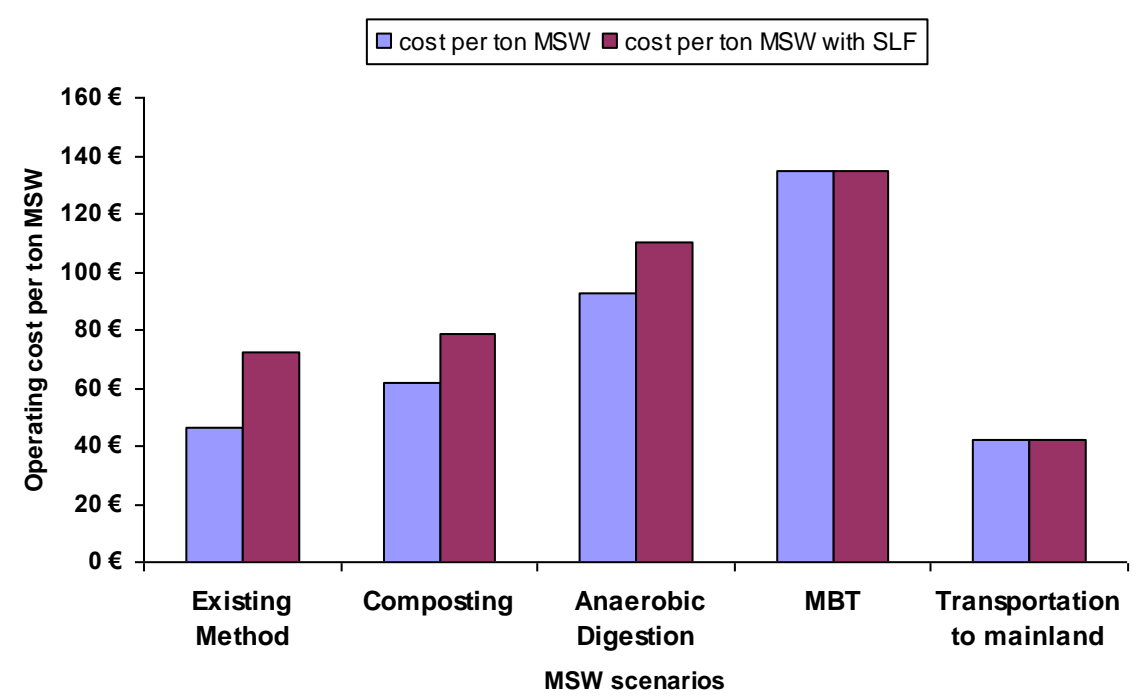

Figure 8. Economic assesment. Note: SLF stands for Special Landfill Tax (€35/T)

According to Greek legislation 4042/2012, a special landfill tax (SLF) of $€ 35 /$ ton (initial value) is applied on the MSW that are not treated and are disposed of directly to a sanitary landfill. Based on that, the total MSW management cost for each scenario can be adjusted according to equation (1):

$$
\mathrm{TC} \text { corr }=\frac{(\mathrm{GMSW} \cdot \mathrm{IWMC}+\mathrm{SLF} \cdot \mathrm{UMSW})}{\mathrm{GMSW}}
$$

where

TCcorr = adjusted total MSW management cost after including SLF ( $€ /$ tn);

GMSW = Total MSW generated in Syros ( $\mathrm{t} / \mathrm{y})$;

IWMc = Management cost of MSW as calculated by LCA-IWM (€/t);

$\mathrm{UMSW}=$ Untreated MSW disposed of directly to the landfill without pretreatment (t/y);

SLF = Special landfill tax (€35/ton applied to untreated MSW disposed of directly to the landfill). In the case of scenario 5 only, SLF becomes equal to the gate fee (a $€ 35 / t$ was used) that is charged by the main MBT facility in Athens for all incoming MSW.

Based on the above, the adjusted total management cost (investment + operating) for each of the 5 scenarios is included in Figure 8 (right column for each scenario). According to Figure 8 , the least expensive scenario is still the 5 th (off-site transportation) followed by the $4^{\text {th }}(\mathrm{MBT})$. In the case of transportation, the landfill tax ( $€ 35 /$ ton) is not applied to the commingled MSW transported to the mainland, since MSW passes through the main MBT plant of Athens that precedes the landfill.

Despite the relatively high cost of the MBT facility constructed on site (scenario 4), waste is not taxed, since it is directed to the treatment plant and not to a landfill. A gate fee of $€ 35 /$ ton is applied to the same MSW that is entering the MBT plant based on typical gate fee rates currently in Greece. In scenarios 2 and 3 , only the organic fraction of the wastes passes through the treatment plant; therefore, commingled MSW (residues) do end up directly to the landfill and are, therefore, taxed (as indicated in Figures 2 and 3 respectively). In the case of scenario 1 , the landfill tax raises the total cost of the system to $€ 73 / t$, since practically all MSW (excluding the MDR directed for recycling) end up to the sanitary landfill. In scenario 2 and 3 , total costs after applying the landfill tax raise to $€ 79 / t$ and $€ 110 / t$, respectively. In the case of 
scenario 4 (aerobic MBT facility on island), however, the total management cost remains unchanged, yet the highest, since all residual MSW is directed to the MBT facility and no specific landfill tax applies.

\subsection{Sensitivity Analysis}

For each alternative scenario under study, three sub-scenarios were considered. In each of them $(1,2,3)$, collection percentages of bio-degradable and mixed recyclables (recycling participation rates) were fixed to $70 \%, 40 \%$ and $20 \%$ for both streams, respectively. The corresponding changes in the economical and environmental performances were recorded. The sensitivity analysis results are illustrated in Figures 9 and 10.

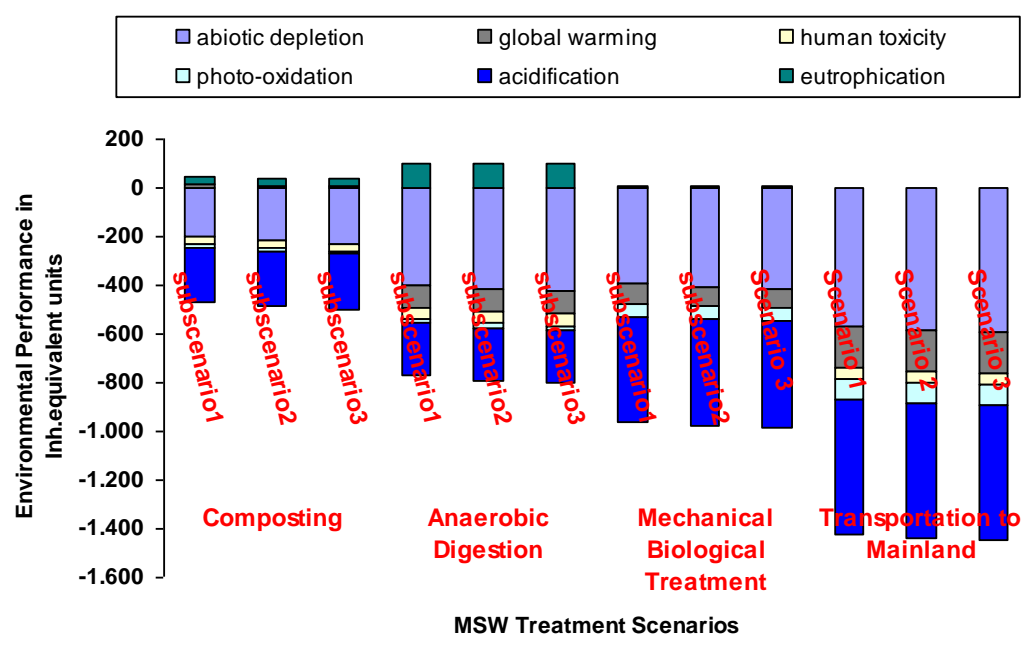

Figure 9. Sensitivity analysis on the environmental performance of 4 MSW Treatment Scenarios ${ }^{(b)}$ (b) Note: Three sub-cases are developed for each scenario i.e. 3 Composting sub-cases, 3 Anaerobic Digestion subcases, $3 \mathrm{MBT}$ sub-cases and 3 Trasportation to mainland subcases. Collection percentages of biodegradables and mixed recyclables for each treatment scenario: $70 \%$ in $1^{\text {st }}$ sub-case, $40 \%$ in $2^{\text {nd }}$ sub-case, $20 \%$ in $3^{\text {rd }}$ sub-case, respectively

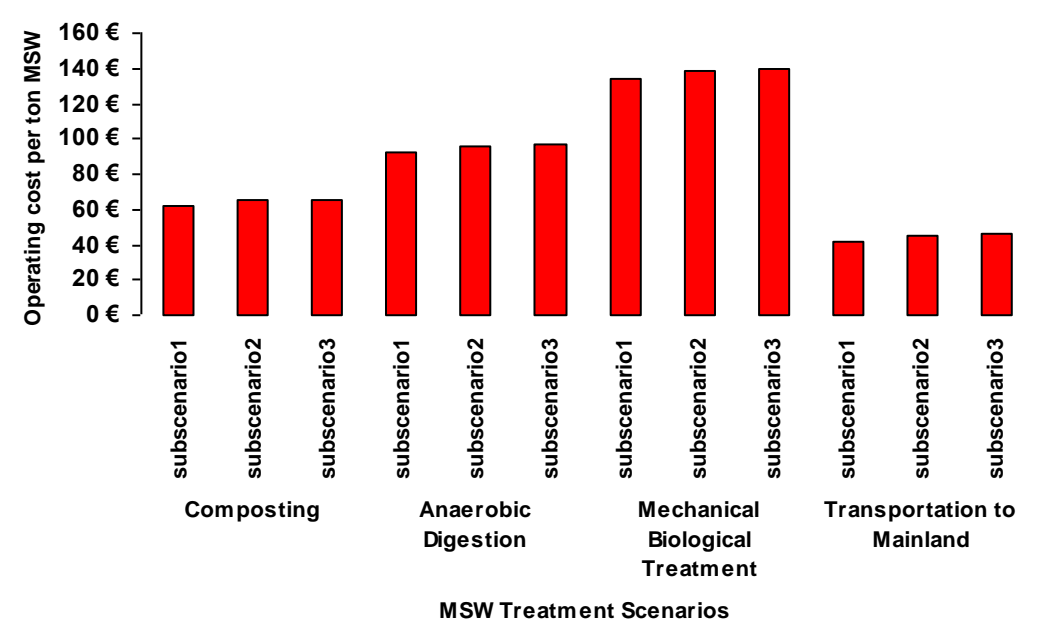

Figure 10. Sensitivity analysis on the economics of four msw treatment scenarios ${ }^{(b)}$

(b) Note: Three sub-cases are developed for each scenario i.e. 3 Composting sub-cases, 3 Anaerobic Digestion subcases, 3 MBT sub-cases and 3 Trasportation to mainland sub-cases. Collection percentages of bio-degradables and mixed recyclables: $70 \%$ in $1^{\text {st }}$ sub-case for each treatment scenario, $40 \%$ in $2^{\text {nd }}$ sub-case; $20 \%$ in $3^{\text {rd }}$ sub-case respectively. 
As can be observed, the global warming index marginally reduces as the recycling participation rates reduce too. This occurs due the fact that as recycling participation rates decrease, the MDR collection demands decrease, leading to less collection itineraries and therefore, to less fuel consumption. However, as is obvious from Figure 9, the overall environmental impacts under the different recycling participation rates remain almost similar. Figure 10 shows that the total cost slightly increases as recycling participation rates decrease, although these increases are considered really small. According to Figures 9 and 10, the increasing MSW source separation percentages do not have a significant positive effect on the overall management cost, despite the common belief for the contrary.

Even if the results of the sensitivity analysis dictate that source separation rates do not affect much the economic and environmental footprints, the EU legislative restrictions and the EU political decisions (i.e. targets set by EU Directives) will eventually determine the future situation on MSW recycling and source separation.

\subsection{Threshold distances to evaluate the sustainability of on-site facilities}

A second task was carried out, within the framework of sensitivity analysis, to calculate the threshold distances over which the construction of new on-site facilities (on the island) would become beneficial. This was done in order to make our conclusions more generic for a wider application in other islands. In order to do that, we sequentially increased the distance between our area of study (Siros Island) and the mainland $(920 \mathrm{~km})$ by $100 \mathrm{~km}$ steps. The distances in which the corresponding costs and environmental impacts became equal to those of direct landfilling, aerobic biological treatment, anaerobic digestion and MBT were recorded. The results are summarized in Table 4.

Table 4. Threshold distances from an island to the mainland over which the on-site construction and operation of the corresponding technologies becomes beneficial *

\begin{tabular}{ccccc}
\hline \multicolumn{5}{c}{ Based on financial criteria } \\
& Landfilling & Composting & Anaerobic digestion & MBT \\
\hline Distance $(\mathrm{km})$ & 1020 & 1620 & 2720 & 4320 \\
\hline Total MSW Management Cost & 45.7 & 90.1 & 61.7 & 132.9
\end{tabular}

$(€ / t)$

\begin{tabular}{ccccc}
\hline \multicolumn{5}{c}{ Based on environmental criteria } \\
\hline & Landfilling & Composting & Anaerobic digestion & MBT \\
\hline Distance (km) & 6720 & 5920 & 4820 & 3320 \\
\hline Environmental impacts (IE units) & 320.8 & 435.0 & 682.5 & 968.1 \\
\hline
\end{tabular}

* For distances higher than the ones shown, it is beneficial to construct and operate the corresponding facilities onsite (on the island). In the other case, transportation off-island remains beneficial

For example, Table 4 indicates that if the distance between the island and the mainland is greater than $1020 \mathrm{~km}$, then the construction and operation of a new landfill in the island is beneficial based on financial criteria only. If the distance becomes greater than $6720 \mathrm{~km}$, then the construction of the on-site landfill becomes beneficial with regard to environmental criteria only. These distances could be broken down to specific environmental impacts (i.e. abiotic depletion, human toxicity, acidification etc) or economic criteria (i.e. capital investment cost, operating cost) and used in a wider variety of studies to investigate whether transfer of MSW for further treatment in the mainland could be (or not) an effective option for MSW treatment in other small islands.

The availability of waste treatment installations of enough capacity in the mainland will highly affect the results. The global economical and environmental impact will obviously change according to whether the mainland facilities need to be enlarged or whether additional ones need to be constructed.

\section{Conclusions}

The cost and LCA based methodology presented here can be applied in archipelago small islands to calculate whether transportation of wastes is beneficial as opposed to on-site construction of waste 
facilities. The LCA results depend highly on the boundaries of the analysis and on whether a local or a global scale of analysis is selected. Our results indicate that transportation of wastes outside the island is beneficial both environmentally and economically up to a certain distance. Above that distance, the onsite construction and operation of new facilities becomes beneficial. Specific conclusions of this work are:

- Transportation was the scenario with the lowest total environmental impacts compared to all other four on-site treatment scenarios. The overall environmental performance of the transportation scenario was -1425 IE followed by the on-site aerobic MBT scenario with -956 IE. The environmentally worse scenario was the one of direct landfilling with -307 IE.

- After taking into consideration the landfill tax applied to untreated wastes directed for landfilling, the least expensive scenario was the off-site transportation (scenario 1) with a total cost of $€ 42$ / ton. The most expensive scenario was still the aerobic MBT scenario (scenario 4), with a total cost $€ 134 / t$. Direct landfilling was the second least expensive scenario with a total cost of $€ 73 / t$.

- Sensitivity analysis showed that changes recycling participation rates (both for MDR and biodegradables) produce minimal changes to the total cost and to the environmental impact.

- Table 4 presents the threshold distances above which the construction and operation of on-site waste management facilities becomes beneficial. These distances vary depending on whether the criteria are financial or environmental. The environmental criteria result to higher threshold distances compared to the financial criteria, except in the case of the MBT plant.

\section{References}

Abeliotis K. (2011), Life Cycle Assessment in Municipal Solid Waste Management- Integrated Waste Management, Intech ISBN: 978-953-307-469-6, 1, 465-482.

Antonopoulos I.S., Karagiannidis A., Tsatsarelis T. and Perkoulidis G., (2012), Applying Waste Management Scenarios in the Peloponnese Region in Greece: A Critical Analysis in the Frame of Life Cycle Assessment, Environmental Science and Pollution Research, 20(4), 2499-2511.

Bourtsalas A.H., Themelis N.I. and Kalogirou E. (2011), Description of Existing Management Situation on Municipal Solid Waste for the Regions Of Greece, Earth Engineering Centre, Columbia University (in Greek), http://docplayer.gr/3847960-Perigrafi-tis-yfistamenis-katastasis-diaheirisis-astikon-stereon-apovliton-a-s-agia-tis-perifereies-tis-ellados.html (assessed Feb. 2016).

Calabró P.S. (2010), The effect of separate collection of municipal solid waste on the lower calorific value of the residual waste, Waste management and Research, 8, 754-758.

Calabró P.S., Gori M. and Lubello C. (2015), European trends in greenhouse gases emissions from integrated solid waste management, Environmental Technology, 36(3-16), 2125-2137.

Chen M.C., Ruijs A. and Wesseler J. (2005), Solid Waste Management on small islands: The case of Green Island, Taiwan, Resources, Conservation and Recycling, 45(1), 31-47.

Finnveden G., Johansson J., Lind P. and Moberg A. (2005), Life cycle assessment of energy from solid waste-part 1: general methodology and results, Journal of Cleaner Production, 13(3), 213-229.

Den Boer E., Den Boer J. and Jager J. (2005), Waste Management Planning and Optimisation, Handbook for Municipal Waste Prognosis and Sustainability Assessment of Waste Management Systems, LCA-IWM. Darmstadt, Germany, 22-306.

Denison R. (1996), Environmental Life-Cycle Comparisons of Recycling, Landfilling, and Incineration: A Review of Recent Studies, Annual Review of Energy and Environment, 21, 191-237.

Diaz L.F. (2007), Resource and Environmental Management in Islands, Waste Management (editorial), 27(3), 325-326.

Gentil E. C., Damgaard A., Hauschild M., Finnveden G., Eriksson O., Thorneloe S., Kaplan P. O., Barlaz M., Muller O., Matsui Y., li R., Christensen T.H. (2010), Models for Waste Life Cycle Assessment: Review of Technical Assumptions, Waste Management, 30(12), 2636-2648.

Georgakellos D., (1999), Life Cycle Analysis: A Systematic Instrument in Environmental Management, 49(1-4), Spoude, University of Piraeus. 
Guinee J.B., Gorree, M., Heijungs R., Huppes G., Kleijn R., DeKoning A., Van Oers, L., Wegener Sleeswijk A., Suh S., Udo deHaes H.A., De Bruijn H., Huijbregts M.A.J., Lindeijer E., Roorda A.A.H., Van der Ven B.L., Weidema B.P., (2001), Handbook on Life Cycle Assessment: Operational Guide to the ISO Standards, Kluwer Academic Publishers, Dordrecht.

ISO 14040 (1997), Environmental Management Life Cycle Assessment Principles and Framework, International Organization for Standardization, Geneva, Switzerland.

ISO 14041 (1998), Environmental Management - Life Cycle Assessment- Goal and Scope Definition and Inventory Analysis, International Organization for Standardization, Geneva, Switzerland.

ISO 14042 (2000a), Environmental Management- Life Cycle Assessment- Life Cycle Impact Assessment, International Organization for Standardization, Geneva, Switzerland.

ISO 14043 (2000b), Environmental Management- Life Cycle Assessment- Life Cycle Interpretation, International Organization for Standardization, Geneva, Switzerland.

ISO 14044 (2006), Environmental Management Life Cycle Assessment Requirements and Guidelines, International Organization for Standardization, Geneva, Switzerland.

Khoo H.H. (2009), Life Cycle Impact Assessment of Various Waste Conversion Technologies, Waste Management, 29(6), 1892-1900.

Koneczny K. and Pennington D.W. (2007), Life Cycle Thinking in Waste Management: Summary of European Commission's Malta 2005 workshop and Pilot studies, Waste Management, 27(8), S92-S97.

Koroneos J.K. and Nanaki E.A. (2012), Integrated Solid Waste Management and Energy Production - A Life Cycle Assessment Approach: The case study of the city of Thessaloniki, Journal of Cleaner Production, 27, 141-150.

Lalas L., Georgopoulou E., Gidarakos E., Gekas R., Lasaridi A., Mavropoulos A., Mirasgentis S., Selas N. (2007), Estimation of Generalized Impact and Cost of Solid Waste Management Institute of by-law Local Authority, Athens.

Laurent A., Bakas I., Clavreul J., Bernstad A., Niero M., Gentil E., Haushild M. Z., Christensen T. H., (2013), Review of LCA studies of Solid Waste Management Systems - Part I: Lessons Learned and Perspectives, Waste Management, 34(3), 573-588.

Liamshanguan C. and Gheewala S.H. (2008), LCA: A Decision Support Tool for Environmental Assessment of MSW Management Systems, Journal of Environmental Management, 87(1), 132-138.

Malatesta S., Schmidt M., Pecorelli V., Di Pietro A. and Cajiao M. A., (2015), The Right place. Solid Waste Management in the Republic of Maldives: Between Infrastructural measures an Local Practices, Miscellanea Geographica -Regional Studies on Development, 19(2), 25-32.

Manfredi S., Tonini D. and Christensen T.H. (2011), Environmental Assessment of Different Management Options for Individual Waste Fractions by Means of Life-Cycle Assessment Modelling, Resources, Conservation and Recycling, 55(11), 995-1004.

Mendez M.R., Aramaki T. and Hanaki K. (2004), Comparison of the environmental impact of incineration and landfilling in São Paulo City as determined by LCA, Resources Conservation and Recycling, 41(1), 47-63.

Parkes O., Lettieri P. and Bogle I.D.L. (2015), Life cycle assessment of integrated waste management systems for alternative legacy scenarios of the London Olympic Park, Waste Management, 40, 157-166.

Pirotta F.J.C., Ferreira E.C. and Bernardo C.A. (2013), Energy recovery and impact on land use of Maltese municipal solid waste incineration, Energy, 49(1), 1-11.

Shamshiry E, Nadi B., Mokhtar M. B., Komoo I., Hashim H.S. and Yahaya N. (2011), Integrated Models for Solid Waste Management in Tourism Regions: Langkawi Island, Malaysia, Journal of Environmental and Public Health, Article ID 709549, 2011, pp 1-5.

Shams Fallah F., Vahidi H., Pazok, M., Akhavan-Limudehi F., Aslemand A.R. and Samiee Zafarghandi R. (2013), Investigation of Solid Waste Disposal Alternatives in Lavan Island Using Life Cycle Assessment Approach, International Journal of Environmental Research, 7(1), 155-164.

Skordilis A. (2004), Modeling of Integrated Solid Waste Management Systems in an Island, Resources, Conservation and Recycling, 41(3), 243-254.

Song Q., Wang Z. and Li J. (2013), Environmental Performance of Municipal Solid Waste Strategies based on LCA method: A case study in Macau, Journal of Cleaner Production, 57, 92-100. 
Tallei T.E., Iskandar J., Runtuwene S. and Filho W.L. (2013), Local Community-based Initiatives of Waste Activities on Bunaken Island in North Sulawesi, Indonesia, Research Journal of Environmental and Earth Sciences, 5(12), 737-743.

Tan R.B. and Khoo H.H. (2006), Impact assessment of waste management options in Singapore, Journal of the Air and Waste Management Association, 56, 244-254.

Willmott L. and Graci S.R. (2012), Solid waste management in Small Island Destinations, Teoros: Rev. Res. Tourism 1, (6), Innovations in Sustainable Tourism, 71-76

Zis T., Bell M. G.H., Tolis A. and Aravossis K. (2013), Economic Evaluation of Alternative Options for Municipal Solid Waste Management in Remote Locations, Waste and Valorization, 4(2) pp 287-296. 